\title{
Biodiversity and climate change in relation to the Natura 2000 network
}

\author{
M. Harley ${ }^{1}$, Y. de Soye ${ }^{2}$, B. Dickson ${ }^{3}$, G. Tucker ${ }^{4}$, and G. Keder ${ }^{5}$ \\ ${ }^{1}$ AEA, Harwell, UK \\ ${ }^{2}$ IUCN, Brussels, Belgium \\ ${ }^{3}$ UNEP-WCMC, Cambridge, UK \\ ${ }^{4}$ IEEP, London, UK \\ ${ }^{5}$ Axiom, Brussels, Belgium
}

Received: 22 December 2008 - Revised: 25 February 2009 - Accepted: 3 April 2009 - Published: 14 April 2009

\begin{abstract}
This project will provide the European Commission (EC) with an overview of the likely impacts of climate change on biodiversity in the European Union (EU), particularly within the Natura 2000 (N2K) network of protected areas, and indications of how the design and implementation of current policy might need to be adapted to ensure that the EU delivers its commitment to halt biodiversity loss by 2010 and beyond. The study will identify those species and associated habitats that are likely to be most vulnerable to climate change and the steps required to protect the integrity of the network from negative effects. The study will also assess the impacts of large-scale renewable energy schemes (wind parks, hydroelectric schemes and tidal barrages) on biodiversity and produce guidelines on the sorts of measures that might be used to maintain and protect $\mathrm{N} 2 \mathrm{~K}$ sites.
\end{abstract}

\section{Introduction}

Commissioned by DG Environment (Nature and Biodiversity), this 18-month study (which began in January 2008) aims to:

- Review the impacts of climate change on Europe's biodiversity.

- Assess the implications of climate change for the EU "2010 and beyond" target.

- Identify threats from climate change to the N2K network.

- Examine the effects of renewable energy schemes on biodiversity and the $\mathrm{N} 2 \mathrm{~K}$ network.

The project is being delivered through four "tasks" and by a team comprising AEA, Axiom, IEEP, IUCN (lead partner) and UNEP-WCMC. The work will completed in June 2009.
Task 1: To review current evidence for the impacts of climate change on Europe's biodiversity

The review encompasses terrestrial, freshwater, coastal and marine environments and focuses on the nine biogeographic regions and 23 "broad" habitat classes that characterise the Natura 2000 network. Its starting point is IPCC's Fourth Assessment Report (AR4) (IPCC, 2007), which provides a sound contextual setting and extensive reference lists. The review also covers a wide range of projects funded by the EC, Member State governments and their agencies, NGOs and research institutes (e.g. MACIS and ALARM).

The task report draws on both observational data and the outputs of computer simulation models. It concentrates on the physical effects of climate change on biodiversity. These include warming temperatures, changing precipitation patterns, increasing sea surface temperature and sea level rise. Consideration is also given to the increasing frequencies of extreme events such as floods, droughts, storms and wild fires. The sorts of impacts already being witnessed or that may be expected include the movement and extinction of species and the changing composition and loss of habitats.

Correspondence to: M. Harley

(mike.harley@aeat.co.uk)

Published by Copernicus Publications. 
Task 2: To assess the implications of climate change for the ability of the EU to halt biodiversity loss by 2010 and beyond

The purpose of this task is to examine the implications of climate change for EU biodiversity policy commitments. Its foundation is an assessment of the vulnerability to climate change of a range of European species and, where possible, associated habitats.

Whilst the Task 1 review identifies a wide body of evidence on climate change impacts, the quality, diversity and scale of the information varies considerably amongst taxa and between regions, and precludes direct comparisons of vulnerability from being made. Instead, data from a number of recent modelling studies are being used as the source material for the vulnerability assessments. These provide comprehensive datasets on key taxanomic groups and include work by Thuiller (2004) and Thuiller et al. (2005) on vascular plants, Araujo et al. (2006) on reptiles and amphibians, Huntley et al. (2007) on breeding birds, and Settele et al. (2008) on butterflies. Particular attention is given to species and associated habitats of Community interest, as listed in Annex I or II of the Habitats Directive (EC, 1992) and Annex I of the Birds Directive (EC, 1979), and migratory birds referred to in Article 4 of the Birds Directive.

An impact assessment framework (Fig. 1a) compares the sensitivity of species with their exposure to climate change and produces a qualitative measure of impact (low to high). The measure of sensitivity of a species to climate change relates to changes in potentially suitable climate space from its current predicted distribution to its projected future distribution. The measure of exposure is based on IPCC's SRES scenarios (A1F1, A2, B2, B1) and associated climate projections for three time slices (2050s, 2080s and 2100).

A vulnerability assessment framework (Fig. 1b) then compares the impact assessment outputs with the adaptive capacity of species to produce a qualitative measure of vulnerability (low to high). Judgements on adaptive capacity consider a range of ecological traits that might constrain the ability of species to adapt autonomously to climate change. These include small populations and/or ranges in Europe, declining populations in Europe, low survival and/or productivity rates, long generation times, low genetic diversity, specialised and uncommon habitat requirements, and narrow niches. For species with less than $70 \%$ overlap between current predicted distribution and projected future distribution, an additional assessment is made using traits indicative of their likely colonisation ability: barriers to dispersal, limited dispersal and/or colonisation ability, and distributions limited mainly to fragmented habitats.

At the time of writing, impact and vulnerability assessments are being carried out for a range of species of Community interest selected from the modelling studies cited above. These are identifying which species are likely to experience high levels of impact and then, in turn, high levels of vulnera- a) Impact assessment

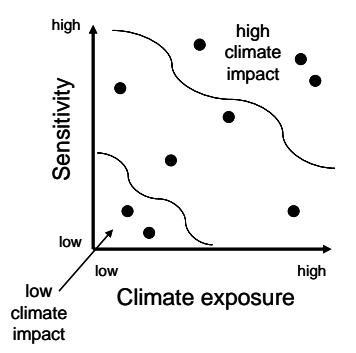

b) Vulnerability assessment

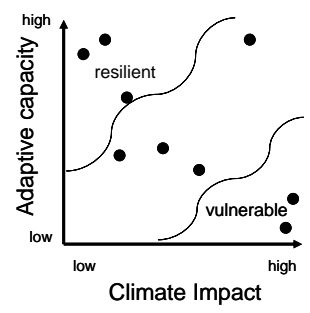

Figure 1. Impact and vulnerability assessment frameworks (based on IPCC's AR4).

bility to climate change. It will also be possible to make subjective appraisals of those species groups and habitat types that are likely to be most vulnerable to climate change in Europe.

The vulnerability assessments will then be used to inform the identification of threats posed to EU biodiversity policy by climate change. Recommendations will be made on how policies might be adjusted to better deliver the EU's biodiversity commitments. There will be a focus on opportunities within the Habitats and Birds Directives and the Commission's Communication on "Halting the loss of biodiversity by 2010 - and beyond". The need for greater policy coherence across and between sectors will also be considered.

\section{Task 3: To assess the threats of climate change to the Natura 2000 network}

The outputs of the vulnerability assessments carried out in Task 2 are being used as the basis for this task. The sites within the N2K network at which species and associated habitats of Community interest that are likely to be most vulnerable to climate change occur will be identified and those most at threat from climate change highlighted.

This will inform an analysis of the policies and practical measures that could help protect the coherence and secure the future of the $\mathrm{N} 2 \mathrm{~K}$ network and maintain or restore Favourable Conservation Status of key species and habitats. Whilst the policy analysis will be relevant to the entire $\mathrm{N} 2 \mathrm{~K}$ network, the data relating to the species and habitats identified as most threatened by climate change will be examined further to assess potential adaptation options (Smithers et al., 2008). These might include:

- Avoiding or reducing impacts related to climate change.

- Increasing the resilience of species and habitats to climate change within their existing ranges and $\mathrm{N} 2 \mathrm{~K}$ sites through habitat enhancement measures to improve survival and productivity rates. 
- Facilitating the dispersal to and colonisation of new areas with suitable climates by creating functional habitat networks and enhancing intervening habitat.

\section{Task 4: To examine the effects of renewable energy schemes on biodiversity and the N2K network}

Renewable energy schemes can have both positive and negative impacts on biodiversity. The respective advantages and disadvantages of large-scale power generation from renewable sources (wind parks, hydroelectric schemes and tidal barrages) for the species and habitats protected in the $\mathrm{N} 2 \mathrm{~K}$ network are being assessed and the effectiveness of EU legislation in minimising potential detrimental impacts on biodiversity considered.

There are two Directives that are relevant to N2K sites and renewable energy schemes. Article 6 of the Habitats Directive $(\mathrm{EC}, 1992)$ requires that projects likely to have significant effects on $\mathrm{N} 2 \mathrm{~K}$ sites be subject to appropriate assessment. The Environmental Impact Assessment Directive (1997) requires that the environmental consequences of projects in all Member States are identified and assessed before authorisation is given.

The sorts of measures that might be used to reduce the impacts of renewable energy schemes on biodiversity and N2K sites, including new technical innovations, are being identified and technical guidelines aimed at minimising the negative impacts on biodiversity produced. These will address the location, planning, EIA, design, construction, operation and monitoring of such schemes in the context of N2K sites. Policy guidelines will sit alongside the technical guidelines; these will link with biodiversity policy and cover restrictions and when and where to promote particular technologies.

\section{Conclusions}

The study will provide an overview of the likely impacts of climate change on biodiversity in the European Union. It will identify those species and associated habitats that are likely to be most vulnerable to climate change, particularly those within the $\mathrm{N} 2 \mathrm{~K}$ network. This will help determine the steps required to protect the integrity of the network and how the design and implementation of current policy might need to be adapted to ensure that the EU delivers its commitment to halt biodiversity loss by 2010 and beyond. The study will also assess the impacts of large-scale renewable energy schemes (wind parks, hydroelectric schemes and tidal barrages) on biodiversity and produce guidelines on the sorts of measures that might be used to maintain and protect $\mathrm{N} 2 \mathrm{~K}$ sites.
Edited by: S. Isoard

Reviewed by: S. McCallum and C. Cowan

\section{References}

Araújo, M. B., Thuiller, W., and Pearson, R. G.: Climate warming and the decline of amphibians and reptiles in Europe, J. Biogeogr., 33, 1712-1728, 2006.

Council Directive 79/409/EEC of 2 April 1979 on the conservation of wild birds, http://ec.europa.eu/environment/nature/legislation/ birdsdirective/index_en.htm (last access: 14 April 2009), 1979.

Council Directive 92/43/EEC of 21 May 1992 on the conservation of natural habitats and of wild fauna and flora, http://ec.europa.eu/environment/nature/legislation/ habitatsdirective/index_en.htm, (last access: 14 April 2009), 1992.

Council Directive 97/11/EC of 3 March 1997 amending Directive $85 / 337 / \mathrm{EEC}$ on the assessment of the effects of certain public and private projects on the environment, http://ec.europa. eu/environment/eia/eia-legalcontext.htm (last access: 14 April 2009), 1997.

Huntley, B., Green, R. E., Collingham, Y. C., and Willis, S. G.: A climatic atlas of European breeding birds, Lynx Edicions, Barcelona, 2007.

IPCC Fourth Assessment Report: Climate Change 2007, http: //www.ipcc.ch/, last access: 14 April 2009.

Settele, J., Kudrna, O., Harpke, A., Kühn, I., van Swaay, C., Verovnik, R., Warren, M., Wiemers, M., Hanspach, J., Hickler, T., Kühn, E., Van Halder, I., Veling, K., Vliegenthart, A., Wynhoff, I., and Schweiger, O.: Climatic risk atlas of European butterflies, Pensoft, Sofia, 2008.

Smithers, R. J., Cowan, C., Harley, M., Hopkins, J. J., Pontier, H., and Watts, O.: England Biodiversity Strategy climate change adaptation principles - conserving biodiversity in a changing climate, Defra, 2008.

Thuiller, W.: Patterns and uncertainties of species' range shifts under climate change, Global Change Biol., 10, 2020-2027, 2004.

Thuiller, W., Lavorel, S., Araújo, M.B., Sykes, M., and Prentice, I. C.: Climate change threats to plant diversity in Europe, Proceedings of the National Academy of Sciences, USA, 102, 82458250, 2005.

\section{Project relationships}

This study has close relationships with two key projects funded by DG Research:

MACIS (Minimization of and Adaptation to Climate change Impacts on biodiver Sity), http://www.macis-project.net/links.html, last access: 14 April 2009.

ALARM (Assessing LArge scale environmental Risks for biodiversity with tested Methods), http://www.alarmproject.net/alarm/, last access: 14 April 2009. 